\title{
Rethinking suicide methods and motivation
}

\author{
Alice Muirhead
}

\section{University of Northern British Columbia}

Several months ago, I was speaking with a high school teacher about the difficulties many young people face when she shared the following story with me. A student had been absent from school for a few days, and when questioned, his friends replied that he had been caught vandalizing cars as part of gang initiation, was in jail, and would be back the following week. He returned the following week and attended school for several days before going missing again. This time however, he had been hospitalized for third degree burns, the result of being repeatedly dosed in body spray and lit on fire, an act that he agreed to. He spent months recovering and will carry scars for the rest of his life.

This story left me with many questions about adolescent development, the desire to belong, and how parents, schools, and communities can address self harm to support the development of strong, healthy individuals. Thinking about the story, and researching self-harm, I came to the conclusion that adolescents who have a well-defined sense of identity, rooted in knowledge of their personal, family, and community history, are able to envision who they can be in the future. With a clear idea of who they can be in the future, young people are less likely to participate in self destructive behaviour. ${ }^{1-3}$

The term parasuicide is used by some researchers to describe deliberate self-harm in the absence of suicide ideation, while other researchers use the term as a synonym for attempted suicide. ${ }^{4-6}$ Using either definition, literature shows that parasuicide is a strong predictor of future suicide completion. ${ }^{4-6}$ Therefore, I suggest that the term "parasuicide" could encompass self-harm, selfmutilation, eating disorders, and/or problematic substance use: all behaviours that indicate a lack of self-care and slow, possibly unconscious, suicide attempt. In opposition to the definition that suggests self-harm can occur with no intent to cause death, I suggest that the intent to die is present whether the individual is able to articulate the intention or not. ${ }^{4}$ Suicides are generally thought of as lives ending quickly through hanging, suffocation, poisoning or jumping; but perhaps suicide comes in many other forms, some of them that occur more slowly.

Factors that predispose an individual for suicide include mental illness, abuse, loss of a loved one early in life and a family history of suicide. ${ }^{2}$ In the presence of these predisposing factors, divorce, pressure to succeed, conflict with the law, financial difficulties and rejection by society are thought to contribute to the creation of crisis and precipitate suicide attempts. ${ }^{2}$ Contributing factors, including physical illness, sexual identity issues, isolation, and an unstable family environment can also make an individual more prone to attempting or completing suicide., ${ }^{2,5}$ These predisposing, precipitating, and contributing factors are similar, if not identical to, risk factors for self-harm, disordered eating, and substance abuse. ${ }^{4}$

Michael Chandler ${ }^{1}$ argues that the question for researchers concerned with suicide should not be why do people commit suicide, but why, in the face of so many obstacles throughout our lives, do more of us not? I suggest this question can be expanded as many people experience loss, rejection, unstable family environments and various other problems without resorting to self-harm, eating disorders, or substance abuse. Research on resilience, family and social support, and participation in academic and extracurricular activities shows that young people must have a clear idea of who they are, and who they will be in the future, to act in a manner that is life-preserving, rather than self-destructive..$^{1-3,7-10}$ Having a clear idea who you are requires knowledge of your history, including the history of your family, community and culture. ${ }^{1}$ With a clear picture of who you are, it becomes easier to imagine the person you will be, including the career you might pursue or the family you might build. I believe that, in supporting the formation of identity in adolescents parents, schools, - 
and communities will support the existence of adolescents who care about their well-being and who are inclined toward self-preservation rather than self-destruction.

The suggestion that adolescents with a strong sense of identity are less likely to participate in self-destruction in any form - requires further research and discussion. The potential of further research and discussion includes strong, resilient young people inclined toward self-care and self-preservation, a goal worth striving for.

\section{References}

1. Chandler MJ, Proulx T. Changing selves in changing worlds: youth suicide on the fault-lines of colliding cultures. Arch Suicide Res. 2006; 10(2): 125-140. Available from: http://www2.psych.ubc.ca/ chandlerlab/Chandler\%20 \&\%20Proulx\%20(2006a).pdf

2. Everall RD, Altrows KJ, Paulson BL. Creating a future: a study of resilience in suicidal female adolescents. J Couns Dev. 2006; 84I: 461-471.

3. Roy A, Sarchiapone M, Carli V. Low resilience in suicide attempters. Arch Suicide Res, 2007; 11: 265-269.

4. Welch Shaw S. A review of the literature on the epidemiology of parasuicide in the general population. Psychiatric Serv. 2001; 52(3): 368-375. Available from: Psychiatry Online: http://ps.psychiatryonline.org/data/Journals/ PSS/3563/368.pdf

5. Ung EK. Youth suicide and parasuicide in Singapore. Ann Acad Med Singapore, 2003; 32(1): 12-8. Available from: http://www.ncbi.nlm.nih.gov/ pubmed/12625092

6. Jenkins GR, Hale R, Papanastassiou M, Crawford MJ, Tyrer P. Suicide rate 22 years after parasuicide: cohort study. BMJ, 2002; 325: 1155. Available from: http://www.bmj.com/highwire/filestream/391639/field_highwire_article_ pdf/0/1155.full.pdf

7. Chandler MJ, Proulx T. Personal persistence and persistent people: continuities in the lives of individual and whole cultural communities. In: Sani F, editor. Selfcontinuity: individual and collective perspectives. New York: Pschology Press; 2008. Available from: http://www2.psych.ubc. $\mathrm{ca} /{ }^{\sim}$ chandlerlab/Chandler\%20\&\%20Proulx\%20(2008).pdf

8. Canada. Suicide prevention: it's your health. Ottawa: Health Canada; 2010. Available from: http://www.hc-sc.gc.ca/hl-vs/iyh-vsv/diseases-maladies/ suicide-eng.php

9. Simpkins SD, Vest AE, Pearce Dawes N, Newman KI. Dynamic relations between parents' behaviours and children's motivational beliefs sport and music. Parent Sci Pract. 2010; 10: 97-118.

10. Babiss LA, Gandwisch JE. Sports participation as a protective factor against depression and suicide ideation in adolescents as mediated by self-esteem and social support. J Dev and Behav Pediatr. 2009; 30: 376-384.

\section{Alice Muirhead}

Alice Muirhead is a MSc student in the Community Health Science program at the University of Northern British Columbia. Her research is focussed on the expectations parents have of their children involved in competitive sport, and the impact these expectations have on children's sport experiences. When she isn't researching or writing, Alice coaches alpine ski racing, runs and teaches yoga. In all her work, Alice strives to promote wellness through healthy living. 